\title{
THE GOLDILOCKS PARADOX: THE NEED FOR INSTRUCTOR PRESENCE BUT NOT TOO MUCH IN AN ONLINE DISCUSSION FORUM
}

\author{
Elizabeth Larson, Grand Canyon University \\ Jacob Aroz, Grand Canyon University \\ Eric Nordin, Grand Canyon University
}

\begin{abstract}
Effective communication is central in the completion of most endeavors; however, a failure to communicate clearly or effectively can be commonplace and difficult to resolve. Communication within the online classroom is fraught with misinterpretations as there is a lack of real-time communication between instructors and students. Gaining a better understanding of what students expect in their communications with instructors can help alleviate the difficulties associated with communication in the online classroom. As such, the purpose of this study was to examine student perceptions and expectations regarding communications within their instructors in the online discussion forum. The critical issues that this study sought to investigate include the following: student expectations of the frequency of communication with instructors, the expected amount of communication, and how rapidly students expect instructor to respond to their posts. Findings from the study demonstrate that students desire to have engagement with their instructor, but in a balanced manner. Students wish to have an instructor that is actively engaged throughout the school week but not so much so that it will overwhelm their ability to interact with others.

Online education has seen tremendous growth in higher education as more universities have started to offer different modalities of learning. As of 2014, it is estimated that over $28 \%$ of students enrolled at a higher learning institution completed some, if not all, of their coursework online (Allen \& Seaman, 2016). While there is a considerable amount of research on online education and student engagement, the impact of instructor engagement has not been as thoroughly researched (Seaton, 2014). Furthermore, student perceptions on instructor engagement has not received significant attention in research. This is an important gap as overall, research shows that positive learning outcomes is strongly linked to student involvement, engagement, and their perception of belongingness (Schwehm, Saxton, \& Stuckey, 2017).

The ability to communicate in an effective

manner is essential to developing rapport within the online classroom, facilitating relationships between students and instructor, completing tasks, and engendering a supportive and edifying community. Online communications frequently struggle to achieve these goals given the lack of face-to-face contact and real-time communication. This disconnect between students and instructors can further complicate this process, as the expectations and prospections of communications may not be clear to either party. As such, the purpose of this study was to investigate student perceptions of instructor communication within the discussion forum in an online classroom. The goal was to gain a better understanding of student expectation and perceptions of communication, and in return, online instructors can have the ability to create and develop improved online
\end{abstract}


presence and communication strategies to serve their students.

\section{LITERATURE REVIEW}

\section{Relationships}

The development of positive relationships between students and instructors is a critical component to student success. Relationships in the online classroom regularly develop within the discussion forum of the online classroom, as this is that area in which students and instructors interact frequently. There are several problematic aspects of communicating within the discussion forum as indicated by literature regarding online classroom communication. However, as Roby, Ashe, Singh, and Clark (2013) pointed out, there is often miscommunication within the discussion forum between students and instructors because expectations about the type of communication and the meaning behind communications can be unclear. Given the text-only nature of the discussion forum, the meaning and nuanced aspects involved in communication can often be lost by both the instructor and the student (HolmbergWright \& Wright, 2012). The asynchronous feature of the discussion forum can also lead to misunderstandings and miscommunication as the time-delay in the system can cause both instructors and students to misconstrue the complexities and intricacies that are apparent in real-time communication (Clarke, 2014). Kahu (2013) further noted that the lack of human interaction within a discussion forum setting could prevent perceptions of engagement from emerging and could lead to a lack of motivation among students. In essence, the dearth of real-time, face-to-face interaction can create an environment in which both students and instructor believe there is a lack of community and rapport. Cultural differences may also play a role in miscommunication within the discussion forum as the subtle nuances of sociocultural traits is lost (Lim, Morris, \& Kupritz, 2007). A difference in educational levels or use of vernacular may prevent relationships from developing, as instructors may believe students are not using appropriate language, and student may perceive a lack of understanding from instructors (Holmberg-Wright \& Wright, 2012). These issues can often lead to student disengagement and increased rate of attrition.
Theliterature regarding online communications within the classroom has presented several strategies to assuage the difficulties of communicating within the discussion forum. Wang (2013) noted that providing prompt responses to student posts could help develop stronger relationships between instructors and students. This could help address issues related to the asynchronous nature of the discussion forum setting. The level of responsiveness of the instructor, meaning how they craft these communications based on student need, can also help develop positive relationships in the online classroom (RodriguezKeyes, Schneider, \& Keenan, 2013). If students perceive their instructors are connecting to them directly, they are more likely to believe a positive relationship is developing. Creating a setting in which honest and open communication is encouraged and accepted is another crucial feature of engendering positive relationships within the discussion forum setting (Smart, 2014). When students believe they have the opportunity to share their true thoughts instead of what they believe the instructor desire to hear, improvements in the student-teacher relationship can occur. Instructors can also post different types of response in the discussion forum (Crawford-Freer \& Wiest, 2012) with orientations toward classroom management, social connection developments, posts based on pedagogical percepts, and technical posts (Clarke, 2014). By delivering varied communications within the online discussion forum, instructors may be able to develop a holistic type of communication, which can lead to positive relationships.

By including the above-mentioned strategies within the discussion forum, instructors can create an environment that can produce positive relationship-based outcomes. As Hostetter and Busch (2013) noted, positive relationship-based discussion forum communication can lead to increased student engagement and increased interaction between the instructor and the student. This can create a deeper level of learning by the student and increased instructor satisfaction. Smart (2014) indicated that positive relationships in the online classroom promote a higher level of student achievement, as engaged students are more likely to produce quality work. Students who perceive positive relationships with their instructors often 
develop a greater sense of connection with their instructor, which can lead to positive relationships (Lim et al., 2007). Students who indicate they have a positive relationship with their online instructor are also more likely to adhere to the principles of lifelong learning, as well as develop an increase sense of intellectual curiosity (Kahu, 2013). The ability of instructors to develop positive relationships with student through interactions within the discussion forum plays a vital role in student success and the development of emerging scholars.

\section{Motivation}

The online discussion forum can be a conduit for instructors to promote and sustain student motivation through quality posts and interactions; however, poor quality posts and interaction can lead to decreased levels of student motivation that often produces negative student outcomes. As HolmbergWright and Wright (2012) noted, students who fail to receive quality posts and interactions that promote motivation from their instructors often perceive a lack of connection within the online classroom and with their instructors. This lack of connection and motivation can lead to decreased levels of student engagement, participation, and create a negative view of the online educational environment (Hostetter \& Busch, 2013). Failure to provide adequate feedback that motivates a student is another issue that can lead to decreased levels of motivation on the part of students as students perceive a lack of connection with their instructors (Smart, 2014). Instructors who fail to foster student engagement through motivational posts and interactions within the online discussion forum, can create an environment in which students feel a sense of isolation and detachment from their course and classmates (Wang, 2013). A sense of isolation is one of the frequent complaints among online students, and exhibiting quality posts and interactions can help assuage a sense of isolation (Roby et al., 2013). The perceived lack of feedback and sense of isolation can generate a situation in which students are unable to measure their progress, thus decreasing their level of motivation. As Crawford-Freer and Wiest (2012) indicated, the lack of motivational communication can cause students to develop negative feelings and perceptions about the online classroom environment, which in turn leads to increased rates of attrition.
The creation of motivation-oriented, highquality posts and positive interactions within the online discussion forum can help instructors increase their student's level of motivation. This increased level of motivation, as indicated by the literature, can produce multiple positive effects. Rodriguez-Keyes et al. (2013) posited that motivational posts could help students develop a sense of belonging, decrease levels of fear, and uncertainty. As students begin to perceive themselves as part of a community and make connections, they will become motivated to engage with the community and continue forward with the community (Kahu, 2013). The use of both positive and critical feedback is also crucial toward engendering high-levels of student motivation (Clarke, 2014). Positive feedback can help students to leverage their current skills and abilities. Additionally, positive feedback can help create a high level of ability-confidence (Holmberg-Wright \& Wright, 2012), while critical feedback, when done correctly, can help students remain motivated to improve in areas where their current skill sets are lacking (Lim et al., 2007). Discussion forum posts and interactions that are motivation-oriented can help promote intellectual growth among students and develop higher levels of self-efficiency, a central component for successful online students (Smart, 2014). The use of motivational feedback can help students begin to develop an online identity in which they begin to internalize and actualize themselves as an online student. RodriguezKeyes et al. (2013) also indicated motivational posts could help students develop both affective and cognitive learning skills, thereby developing the learning skill sets students will need to be successful in the online learning environment. By using motivational discussion question responses and creating motivation-oriented interactions, online instructors can help students develop a sense of themselves in the online classroom, foster community-building behaviors, decrease attrition rates, the sense of isolation and fear, the perception of a lack of direction, and increase satisfaction, connectedness, engagement, and continuance.

\section{Involvement}

The level of student involvement within the online classroom can have a salient effect on the student's ability to succeed in their course as well 
as continue in their program of study, and the instructors' participation within the discussion forum can produce both increased or decreased levels of student involvement. There were several aspects of instructor participation within the discussion forum, as noted in the literature, which could produce decreased levels of student involvement. As Rodriguez-Keyes et al. (2013) indicated, a lack of frequent communication between the instructor and student tended to produce decreased level of student involvement, as instructors who communicate with students frequently could help students to garner a higher level of involvement as students perceived they were becoming part of a dialogue-based community. Discussion forum posts and interactions where instructors failed to demonstrate individualization to students frequently created decreased levels of involvement by the student (Holmberg-Wright \& Wright, 2012). Students who perceived their instructors posting pre-written or generic posts within the discussion forum developed a sense of isolation, which produced decreased level of involvement within the online classroom (Clarke, 2014). The failure of instructors to produce quality posts and communication within the discussion forum tended to have higher levels of nonparticipating students, as their students believed the lack of quality posts was an indication of non-involvement by the instructor (CrawfordFreer \& Wiest, 2012). In order to increase levels of student involvement, instructors should work toward producing quality communication within their discussion forums to help student engage in a holistic manner with the material. The failure of instructors to produce involvement-oriented communications and interactions within the discussion forum promoted a reduction concerning the ability of students to actively learn in the classroom, in which students failed to exhibit high levels of intellectual inquiry (Wang, 2013). The disconnect and lack of involvement perceived by students, as noted by Roby et al. (2013), lead to negative perceptions of the student's university, which often produced increased failure rates and levels of attrition.

By using involvement-oriented communication and interactions within the discussion forum, instructors can produce positive student perceptions in addition to instructor-to-student and student-to-student interactions. As Hostetter and Busch (2013) posited, creating a discussion forum that promotes involvement helps the instructor to develop a social presence, which in turn, can lead to students to develop a social presence within the online classroom. An increased perception of presence within the classroom can help students to remain engaged with both the instructor and their peers (Lim et al., 2007). Communications and interactions that encouraged involvement helped students find inclusion within the online classroom, which helped assuage feelings of isolation (Rodriguez-Keyes et al., 2013). By using involvement-promoting posts within the discussion forum, instructors can help encourage the participation of all students, which produces a more diverse area of learning (Kahu, 2013). Involvement-oriented communications and interaction often can lead to higher levels of dialogue, as opposed to conversation where students interact with each other and the instructor on a higher intellectual level (Smart, 2014). In addition, the use of involvement promoting posts allowed students to garner an increased level of connection to the class and to the university, which deceases levels of attrition and dissatisfactory perceptions (Roby et al., 2013). The use of involvement promoting posts, communications, and interactions within the discussion forum by instructors can help promote many of the crucial aspects involved in developing successful online student. Furthermore, these strategies can help students create connections within their classroom, and develop their online personas.

\section{Proximity}

Teaching in the online asynchronous format can present a challenge as the lack of physical interaction can cause students and instructors to perceive a disengagement from the course. Baturay (2011) noted the two main issues of online learning were higher dropout rates and low quality of learning attainment, which could be correlated to limited interaction between the instructor and students. As Aragon (2003) pointed out, teaching and learning are predominately-social endeavors, thus requiring instructors to understand how the effect of distance (geographical, temporal, and psychological) can affect the learning process. 
Social presence may have an impact on student perception of instructor proximity in the online classroom. Furthermore, discussion in the literature generally supports the idea of instructor proximity as most focus on the importance of visible, active engagement by the instructor in the discussion forum (Nandi, Hamilton, \& Harland, 2012).

With the removal of face-to-face interactions, students often perceive a distance toward the instructor, leaving students with feelings of isolation and lack of support (Borup, West, Thomas, \& Graham, 2014). Instructor presence encompasses the "design, facilitation, and direction of cognitive and social processes for the realization of personally meaningful and educationally worthwhile learning outcomes" (Mandernach, 2009, p. 4). As Ross, Gallagher, and Macleod (2013) indicated, proximity or nearness in the online environment "must continually be assembled, as online distance learners progress through the stages of formalized degree programmes and balance their other professional and personal commitments" (p. 52).

Increased instructor-led discussions within the online learning environment may have an impact on providing proximity in the classroom, thus affecting student-learning outcomes. When there is an emphasis to increase social interaction in the online learning environment, it can lead to a reduction in feelings of isolation in students, while increasing student-teacher interaction and cognitive learning (Mayne \& Wu, 2011). Students who have high levels of engagement tend to enjoy being active in the learning process and persist in their academic studies (Mandernach, 2009). It should be noted that research regarding the impact of instructor participation is not conclusive, as some research has found that the level of instructor participation (presence) has had a positive impact on voluntary student participation (Wise, Hamman, \& Thorson, 2006), others found that high level of engagement from the instructor could have the opposite effect (Eom \& Ashill, 2016; Mazzolini \& Maddison, 2007).

There are multiple techniques that can be implemented to increase proximity in the online classroom. Purarjomandlangrudi, Chen, and Nguyen (2016) suggested instructors focus on the learner-instructor interaction using technology.
The integration of technology provides opportunity for "multiple interactions among all the different agents involved-learners, instructors and course designers, tutors, contents, interfaces, administrative staff, code, environments, etc." (Agudo-Peregrina, Iglesias-Pradas, CondeGonzález, \& Hernández-García, 2014, p. 542). Technology provides instructors with the ability to customize content and learning to meet a variety of student needs. Dyer, Larson, Steele, and Holbreck (2015) indicated online learning requires innovation from instructors through the development and utilization of web-based technology tools. Additionally, Horzum (2015) found the usage of online "tools" increased social presence positivity.

Quality of instructor-led discussion is equally as important in the effort to increase proximity. As Thormann and Fidalgo (2014) noted, the expectations for online instructors differ from those of a classroom teacher, thus resulting in a need for an improved skill set of how to facilitate online discussion. Specifically, the online instructor needs to create a positive learning environment, in addition provide participation and activities that students can model their interaction off of. Wang (2013) noted that the proximal gap between online instructor and student could be lessened through the usage of asking open-ended questions, thus resulting in deeper knowledge construction. Mazzolini and Maddison's (2007) study on frequency and nature of instructor participation found students perceived that instructors who were active in the discussion forum and answered many questions to be more "enthusiastic" by their students. Additionally, students "did not appreciate it when instructors mainly posted housekeeping type postings rather than engaging actively in the online discussions" (p. 19).

\section{Personalization}

Personalizing the experience students have in an online classroom are tools to be used to impact feelings of isolation and waning motivation among students. Wang, Shannon, and Ross (2013) determined the loss of personal contact between instructor-student, and student-student as a major concern associated with the online learning environment. Additionally, research shows that online instructors need to be able to teach to a wide 
variety of learning styles (Mestre, 2010). Nandi et al. (2012) pointed out that online discussion forums provide learners with the opportunity to interact with each other, the course material on a deeper level. This provides the potential for "negotiation and internalization of knowledge rather than just rote memorization of knowledge" (p. 6). To help reduce the loss of personal contact and address multiple learning styles, instructors can provide personalized instruction, content, and discussion responses.

The use of web-based technology has been shown to help online instructors provide personalized encounters with students. Mandernach (2009) stated technology provides instructors the ability and opportunity to personalize the learning environment, which can help meet learning objectives and enrich student engagement. Nandi et al. (2012) determined there are three types of student interaction in the online learning environment: student-student interaction, student-instructor interaction, and student-content interaction. Personalized multimedia posted in the discussion forum can help facilitate student interaction on all three levels. As Morris (2011) noted, Web 2.0 technologies can assist instructors in the facilitation of student knowledge construction and student-student collaboration within the online learning environment. Research indicated that student engagement was elevated when the instructor provided personalized instructional content instead of perceived generic content from a publisher or external source (Mandernach, 2009).

Research shows that students perceive the ideal instructor as someone who personalizes his or her interaction with each student by asking follow-up related questions and introduces a close concept or different point of view within their discussion forum responses (Hung \& Chou, 2015; Mazzolini \& Maddison, 2007). Additionally the ideal instructor will address every question before moving onto a new learning objective and provide his or her own opinion on a topic discussed among the students. Instructors should personalize the discussion by identifying and tying student interests to the learning objectives in their responses, thus providing students with the opportunity for meaningful engagement (Mokoena, 2013). Dyer et al. (2015) supported this claim, noting that, "The integration of technology can help students become more invested and engaged in the classroom by making it more interactive and conducive to a classroom of differing learning styles" (p. 128).

\section{Community}

As noted previously, education and particularly teaching, is largely social in nature. Socialization provides students with the ability to create their own learning community. A learning community is a group of learners who share knowledge, values, and ideas in the context of a supportive environment (Yuan \& Kim, 2014). Learning communities can provide students with an environment in which they may experience a sense of proximity with their peers and instructor.

The feeling of community among students has shown to be an indicator of student success. Online students who have a low sense of community tend to have higher dropout rates than their high sense of community counterparts (Bryant \& Bates, 2015). This may be due to the sense of isolation, lack of physical proximity to the instructor, and lack of student-student interaction. Rovai (2002) contended that there is evidence that a strong sense of community may increase student motivation and persistence in a class. Furthermore, Bryant and Bates (2015) noted that success in a learning community is heavily dependent on a learner's engagement within the online classroom through participation and learning activities. Therefore, "Students should be provided with increased affective support by promoting a strong sense of community" (Baturay, 2011, p. 564). Erdem and Gumus (2016) stated that the sense of belonging that stems from learning communities and working within a community may help decrease the perception of isolation and help students do better in their academic studies.

According to Bryant and Bates (2015), the online learning environment affords instructors with the opportunity to build a sense of community through a variety of methods. Research shows that a student's perception of community stems from two main sources: instructor-student interaction and student-student interaction. Social community can be cultivated through instructor efforts on increasing the amount and quality of social interaction. Instructors can focus on quality social interaction through effective use of discussion 
boards, chat sessions, e-mail correspondence, and video or audio conferencing (Baturay, 2011). Additionally, Gao, Zang, and Franklin (2013) stated that instructor engagement in the discussion forum stimulates the sense of community within the online learning environment. To foster a sense of community, research indicates instructors should focus on providing opportunity for active, purposeful, and meaningful interaction. Additionally instructors can focus on creating a "community of inquiry," thus increasing social interaction between students and the instruction (Garrison, 2007). This is in large part due to learning communities providing students with the opportunity to debate, argue, defend, or assess content within the discussion forum (Dyer, Aroz, \& Larson, 2018; Gan \& Zhu, 2007). Previous studies on sense of community (Bruffee, 1993; Dede, 1996; Wellman, 1999; Wellman \& Gulia, 1999) have revealed that there is a positive relationship between the sense of community and information sharing and flow among learners, creating a common commitment to the achievement of goals, satisfaction due to cooperation and teamwork (Bryant \& Bates, 2015).

\section{METHODOLOGY}

This study used a qualitative research method and phenomenological design to help analyze and collect the data relating to student perceptions of online communication within the discussion forum. The qualitative research method allowed the researchers to investigate in an in-depth manner the subtle nuances and complexities of online communication, while the phenomenological design helped the researchers gain a better understand of the thought process of participants in a specific location and environment. The reason behind choosing a qualitative method and phenomenological design over other methods and designs was the intention of the research to examine lived experiences as opposed to data analysis. Qualitative studies are useful in examining personal experience allowing participants to be active in the research process (Therani, Martimianakis, \& Varpio, 2015). The design of the questions allowed participants to choose from multiple answers rather than a yes-no design, which helped elicit richer responses.

\section{Participants}

Participants for this study were students enrolled in an online undergraduate program at a university in the southwestern region of the United States. These participants were students from one specific course, spread out through multiple classes and instructors. The study was open to all students in these classes, and participation was completely voluntary. The population was a convenience sample given the researchers proximity to the research site. No data collection occurred prior to Institution Review Board (IRB) approval.

\section{Results}

The results from this study involved student perceptions of instructor communication and participation within the online discussion forum. Students from different sections of one online course were given the opportunity to participate. A Survey Monkey link was embedded within the Module 7 discussion forum, and students were provided information relating to the amount of communication they expect from an instructor, the frequency in which the instructor interacts within the discussion forum, and the response rate (timeframe) students expect to receive a response from their instructors to their posts within the forum. There were no follow-up electronic or inperson communications relating to the study with the participants once the survey was complete.

\section{Findings}

The following section delineates the results for this study regarding student expectations concerning instructor participation within the discussion forum of an online classroom involving the amount of participation, the frequency of participation, the amount of personal interaction within individual students, and the response times to student posts. The findings indicated that in general, there was a close alignment of student expectations, which meant most students held similar expectations of instructor participation, although there were outlier responses. As such, instructors may need to focus on the individual needs of their individual students as opposed to developing generic participation strategies (Lim et al., 2007). The following findings may be useful for instructors working within the online environment, administrators developing policies and procedure regarding online instruction, and Learning Management System developers, as the findings indicated student expectations regarding instructor interaction within the discussion forum. 
The results from the question regarding student expectations concerning the number of instructor posts per week within the discussion forum indicated the majority of students, $71.11 \%$ expected instructors to provide 5 to 14 posts per week, with 31 students preferring five to nine, while 33 students expected 10 to 14 posts. Ten percent of the students who responded to the survey expected instructors to provide 15 to 19 posts within the discussion forum during the week, and $10 \%$ expected more than 20 posts during the week. The smallest segment of students, $8.89 \%$, expected one to four posts provided by the instructor during the week within the discussion forum. The results indicated that there is an alignment of student expectations concerning instructor participation, and this may be a result of student familiarity concerning instructor participation in previous online courses. One of the central findings from the results of this question relates to the frequency of instructor participation. According to Hostetter and Busch (2013), being present in the online classroom for an online instructor is crucial in order to provide students a perception of frequent interaction and connection with the instructor. Understanding student expectations about the amount of posts within the discussion forum could help current and future online instructor develop strategies to meet such expectations.

Table \#1: What are your expectations of the number of instructor posts per week in the discussion forum?

\begin{tabular}{|c|c|c|}
\hline $\begin{array}{c}\text { Number of } \\
\text { Instructor Posts } \\
\text { Per Week }\end{array}$ & \# of Students & Response rate \\
\hline 1-4 posts & 8 & $8.89 \%$ \\
\hline 5-9 posts & 31 & $34.44 \%$ \\
\hline 10-14 posts & 33 & $36.67 \%$ \\
\hline 15-19 posts & 9 & $10 \%$ \\
\hline 20+ posts & 9 & $10 \%$ \\
\hline Grand Total & 90 & $100.00 \%$ \\
\hline
\end{tabular}

The second question of the survey related to the number of days an instructor should be active within the discussion question forum. The majority of students, $85.15 \%$, believed instructors should be present and posting within the discussion forum between four to seven days. This formed a high majority of responders, which indicated that students expect their instructors to be active within the forum the majority of the week, and this may relate to issues of connectivity and proximity (Roby et al., 2013). Forty-one percent $(46.07 \%)$ of the students surveyed indicated they expected their instructor to be active and posting within the discussion forum at least four days during the week, and $37.08 \%$ of students expected participation on five to seven days. Below the four-day participation mark, responses decreased, as $14.81 \%$ expected three days of participation, $1.12 \%$ expected two days of participation, and $1.12 \%$ expected one day of participation from instructor in the discussion forum. The results from this question indicated that students expect their online instructors to be present and posting during the majority of days during the week. The frequency in which an instructor is present and active within the discussion forum can help alleviate many of the issues students perceive regarding online education (Wang, 2013). By being active during the majority of the days during the week, online instructors may be able to recreate the interactions and connections perceived in a traditional classroom.

Table 2. What are your expectations of the number of days per week instructors should participate in the discussion forum?

\begin{tabular}{|c|c|c|}
\hline Number of Days & \# of Students & Response rate \\
\hline 1 day & 1 & $1.12 \%$ \\
\hline 2 days & 1 & $1.12 \%$ \\
\hline 3 days & 13 & $14.61 \%$ \\
\hline 4 days & 41 & $46.07 \%$ \\
\hline 5-7 days & 33 & $37.08 \%$ \\
\hline Grand Total & 89 & $100.00 \%$ \\
\hline
\end{tabular}

The third question asked students how often they expected to receive a direct response from their instructor to their posts during the week within the discussion forum. This was asked to better ascertain the level of personal interactions students expect from their online instructors. The majority, 52.22\%, indicated they would desire at least one response per week. This finding is aligned with previous research by Smart (2014) that indicated online students desire weekly personal contact with their instructors. When weekly personal contact occurs, students 
perceive a sense of place and belonging within the online classroom. Interestingly, the three additional options for the survey showed relatively similar and smaller responses, as the choice of an expectation of a response to all posts garnered an $11.11 \%$ response rate, more than one post elicited an $18.89 \%$ response rate, and no post - perhaps the most interestinggarnered a $17.89 \%$ response rate. The last response may be due to online students believing there will be little or no interaction with the instructor or the students desiring to have limited interaction with the instructor (Roby et al., 2013). A crucial finding from this question is the majority of students expect weekly interaction and responses from their instructors, and understanding this could help in the development of online instructor participation strategies.

Table 3. How often do you expect to receive a direct response from your instructor to your posts in the discussion forum per week?

\begin{tabular}{|c|c|c|}
\hline $\begin{array}{c}\text { Number of Direct } \\
\text { Responses }\end{array}$ & \# of Students & Response rate \\
\hline All posts & 10 & $11.11 \%$ \\
\hline At least 1 post & 47 & $52.22 \%$ \\
\hline More than 1 post & 17 & $18.89 \%$ \\
\hline No posts & 16 & $17.78 \%$ \\
\hline Grand Total & 90 & $100.00 \%$ \\
\hline
\end{tabular}

The fourth question concerned the timedelay students expected regarding how quickly an instructor responded to their post within the discussion forum. The findings within the question could be useful for online instructors to help manage their time and set priorities concerning activity within the discussion forum (Wang, 2013). The majority of students, $82.02 \%$, expected instructors to respond to their post within one to two days, with 29.21 expecting a one-day response and 52.81 desiring a two-day response. Less than $20 \%$ sought a response after three days, as three days garnered $12.36 \%$, four days elicited a $2.25 \%$, and five days received $3.37 \%$ response. The findings from this question indicated online students desire to have rapid response to their posts within the discussion question forum. This is congruent with Smart's (2014) research, which indicated response times within the online classroom are critical toward student engagement. The central finding from this survey question indicates that students expect a rapid-one-day-response from their instructor to their post within the discussion forum.

Table 4. How quickly do you expect an instructor to respond to your post in the discussion forum?

\begin{tabular}{|c|c|c|}
\hline $\begin{array}{c}\text { Quickness of } \\
\text { Instructor Response }\end{array}$ & \# of Students & Response rate \\
\hline 1 day & 26 & $29.21 \%$ \\
\hline 2 days & 47 & $52.81 \%$ \\
\hline 3 days & 11 & $12.36 \%$ \\
\hline 4 days & 2 & $2.25 \%$ \\
\hline 5 days & 3 & $3.37 \%$ \\
\hline Grand Total & 89 & $100.00 \%$ \\
\hline
\end{tabular}

\section{DISCUSSION}

The ability to communicate in an effective manner within an online setting is a difficult endeavor, and as the inclusion of the online classroom dynamic and the relationships between faculty and students becomes important, the communication process increases in difficulty. The purpose of the study was to elucidate possible strategies for online faculty to ensue in their communications with their students within the online discussion forum. By studying students' perceptions and expectations of faculty communication within the discussion forum, including frequency, response time, and the amount of communicating from instructors, the online classroom can become a place where students feel supported, be a part of a community, and gain a sense of themselves as an online student. Instructors can gain the understanding of what students expect in terms of communication, whereby they can develop interaction and communicational strategies and techniques that meet both the needs and wants of students. Future research could include topics of student expectations of instructor availability on nights and weekends, does the timeliness of an instructor's responses affect learning outcomes, how instructor responses times and frequency affect community building in the online classroom, and how peer-to-peer communication differs from instructor-to-peer communication in the community building process.

\section{LIMITATIONS}

There are several limitations to this study that need to be acknowledged. Several of these limitations present future research opportunities 
that can help provide additional information or best practices that enhance the instructor-student relationship and student learning within an online discussion forum. One limitation of this study was the specific expectations of instructor participation based on university requirements. The participants for this study were in their third online class, and may have familiarity with these expectations, which could have strengthened their desire for a specific number of posts and frequency of posting. Furthermore, these results are for current students who have taken at least two online classes, and thus their expectations may be different from those of a new, incoming student. An additional limitation of the study was that the question regarding the frequency of instructor posts during the week, the survey did not separate the answer "5-7 days," and this lack of specificity might have affected the results of the study. Data demographics (age, gender, race, level of education) were not collected. Future research should address data demographics, delineate instructor expectations, and include new, incoming students. One final note, two participants chose not to answer Question \#2 (frequency of posts) and Question \#4 (quickness of response).

\section{CONCLUSION}

The goal of this study was twofold: to determine the ideal number of days an instructor should be active within an online discussion, and to identify the optimal number of instruction-based responses an instructor should have in an online discussion. The results indicated that the majority of students desired instructors to be active within the discussion forum throughout the school week, but not every day of the week. Instructors need to be active and engaged throughout the week, but should not dominate the discussion. The ideal instructor is active at least four of the seven days in the discussion forum, and has the ability to provide personalized and direct responses for each student at least once during the week. These findings can help provide online instructors with a guide of when and how often they should be active within a discussion forum, thus increasing instructor engagement and student engagement, which is essential in the online classroom. Furthermore it can aid in a student's success as increasing instructor engagement will help elicit a sense of belonging and promote proximity within the classroom. 


\section{References}

Agudo-Peregrina, Á. F., Iglesias-Pradas, S., Conde-González, M. Á., Hernández-García, Á. (2014). Can we predict success from log data in VLEs? Classification of interactions for learning analytics and their relation with performance in VLE-supported F2F and online learning. Computers in Human Behavior, 31, 542-550.

Allen, I. E., \& Seaman, J. (2016). Online report card: Tracking online education in the United States. Retrieved from http:/l onlinelearningsurvey.com/reports/onlinereportcard.pdf

Aragon, S. R. (2003). Creating social presence in online environments. New Directions for Adult \& Continuing Education, 2003(100), 57-68.

Baturay, M. (2011). Relationships among sense of classroom community, perceived cognitive learning and satisfaction of students at an e-learning course. Interactive Learning Environments, 19(5), 563-575.

Borup, J., West, R. E., Thomas, R., \& Graham, C. R. (2014). Examining the impact of video feedback on instructor social presence in blended courses. International Review of Research in Open and Distance Learning, 15(3), 232-256.

Bryant, J., \& Bates, A. J. (2015). Creating a constructivist online instructional environment. Techtrends: Linking Research and Practice to Improve Learning, 59(2), 17-22.

Clarke, L. W. (2014). Digging beneath the surface: Analyzing the complexity of instructors' participation in asynchronous discussion. Online Learning, 18(3), 1-19.

Crawford-Ferre, H., \& Wiest, L. R. (2012). Effective online instruction in higher education. The Quarterly Review of Distance Education, 13(1), 11-14.

Dyer, T., Aroz, J., \& Larson, E. (2018). Proximity in the online classroom: Engagement, relationships, and personalization. Journal of Instructional Research, 7, 108-118.

Dyer, T., Larson, E., Steele, J., \& Holbeck, R. (2015). Integrating technology into the online classroom through collaboration to increase student motivation. Journal of Instructional Research, 4, 126-133

Eom, S. B., \& Ashill, N. (2016). The determinants of students' perceived learning outcomes and satisfaction in university online education: An update. Decision Sciences Journal of Innovative Education, 14(2), 185-215.

Erdem Aydin, I., \& Gumus, S. (2016). Sense of classroom community and team development process in online learning. Turkish Online Journal of Distance Education, 17(1), 60-77.
Gan, Y., \& Zhu, Z. (2007). A learning framework for knowledge building and collective wisdom advancement in virtual learning communities. Journal of Educational Technology \& Society, 10(1), 206-226.

Gao, F., Zhang, T., \& Franklin, T. (2013). Designing asynchronous online discussion environments: Recent progress and possible future directions. British Journal of Educational Technology, 44(3), 469-483.

Garrison, D. R. (2007). Online community of inquiry review: Social, cognitive, and teaching presence issues. Journal of Asynchronous Learning Networks, 11(1), 61-72.

Holmberg-Wirght, K., \& Wright, D. J. (2012). MBA and undergraduate business student perceptions of online courses: Experienced online student verse students who have not taken an online course. Global Education Journal, 1(12), 169-186.

Horzum, M. B. (2015). Interaction, structure, social presence, and satisfaction in online learning. Eurasia Journal of Mathematics, Science \& Technology Education, 11(3), 505-512.

Hostetter, C., \& Busch, B. (2013). Community matters: Social presence and learning outcomes. Journal of the Scholarship of Teaching and Learning, 13(1), 77-86.

Hung, M.-L., Chou, C. (2015). Students' perceptions of instructors' roles in blended and online learning environments: $A$ comparative study. Computers \& Education, 81, 315-325.

Kahu, E. R. (2013). Framing student engagement in higher education. Studies in Higher Education, 38(5), 758-773.

Lim, D. H., Morris, M. L., \& Kupritz, V. W. (2007). Online vs. blended learning: Difference in instructional outcomes and learner satisfaction. Journal of Asynchronous Learning, 11(2), $27-42$.

Mandernach, B. J. (2009). Effect of instructor-personalized multi-media in the online classroom. Instructional Review of Research in Open and Distance Learning, 10(3), 1-19.

Mayne, L. A., \& Wu, Q. (2011). Creating and measuring social presence in online graduate nursing courses. Nursing Education Perspectives, 32(2), 110-114.

Mazzolini, M., \& Maddison, S. (2007). When to jump in: The role of the instructor in online discussion forums. Computers \& Education, 49(2), 193-213.

Mestre, L. S. (2010). Matching up learning styles with learning objects: What's effective? Journal of Library Administration, 50(7/8), 808-829. 
Mokoena, S. (2013). Engagement with and participation in online discussion forums. Turkish Online Journal of Educational Technology, 12(2), 97-105.

Morris, R. D. (2011). Web 3.0: Implications for online learning. Techtrends: Linking Research \& Practice to Improve Learning, 55(1), 42-46.

Nandi, D., Hamilton, M., \& Harland, J. (2012). Evaluating the quality of interaction in asynchronous discussion forums in fully online courses. Distance Education, 33(1), 5-30.

Purarjomandlangrudi, A., Chen, D., \& Nguyen, A. (2016). Investigating the drivers of student interaction and engagement in online courses: A study of state-of-the-art. Informatics in Education, 15(2), 269-286.

Roby, T., Ashe, A., Singh, N., \& Clark, C. (2013). Shaping the online experience: How administrators can influence student and instructor perceptions though policy and practice. Internet and Higher Education, 17, 29-37.

Rodriguez-Keyes, E., Schneider, D. A., \& Keenan, E. K. (2013). Being known in undergraduate social work education: The role of instructors in fostering student engagement and motivation. Social Work Education, 32, 785-799.

Ross, J., Gallagher, M. S., \& Macleod, H. (2013). Making distance visible: Assembling nearness in an online distance learning programme. International Review of Research In Open And Distance Learning, 14(4), 51-67.

Rovai, A. P. (2002) Building a sense of community at a distance. International Review of Research in Open and Distance Learning, 3(1), 1-16.

Schwehm, J., Saxton, J., \& Stuckey, A. (2017). Promoting engagement and community in online Courses: It's all about the writing. Adult Higher Education Alliance, 41.

Seaton, J. J., \& Schwier, R. R. (2014). An exploratory case study of online instructors: Factors associated with instructor engagement. International Journal of E-Learning \& Distance Education, 29(1), 1-16.

Smart, J. B. (2014). The mixed methods study of the relationship between student perceptions of teacher-student interactions and motivation in middle level science. Research in Middle Level Education Online, 38(4), 1-19.

Thormann, J., \& Fidalgo, P. (2014). Guidelines for online course moderation and community building from a student's perspective. Journal of Online Learning \& Teaching, 10(3), 374-388.
Wang, J. (2013). What higher educational professionals need to know about today's students: Online social networks. The Turkish Journal of Educational Technology, 12(3), 180-195.

Wang, C., Shannon, D. M., \& Ross, M. E. (2013). Students' characteristics, self-regulated learning, technology selfefficacy, and course outcomes in online learning. Distance Education, 34(3), 302-323.

Wise, K., Hamman, B., and Thorson, K. (2006) Moderation, response rate, and message interactivity: Features of online communities and their effects on intent to participate. Journal of Computer-Mediated Communication, 12(1), 24-41.

Yuan, J., \& Kim, C. (2014). Guidelines for facilitating the development of learning communities in online courses. Journal of Computer Assisted Learning, 30(3), 220-232. 